\title{
Profitability of farm-scale management strategies against the boll weevil in the tropics: case study from the Colombian Caribbean
}

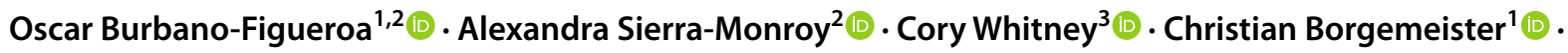 \\ Eike Luedeling ${ }^{3}$ (i)
}

Received: 13 March 2021 / Revised: 28 June 2021 / Accepted: 6 July 2021 / Published online: 26 July 2021

(c) The Author(s) 2021

\begin{abstract}
Decision making in pest management is a challenging task. While pest dynamics are often quite uncertain, such decisions are often based on tenuous assumptions of certainty (economic injury levels and marginal utility approximations). To overcome such assumptions and adequately consider uncertainty, we apply decision analysis to evaluate management strategies used by farmers in the Colombian Caribbean against the boll weevil (BW). We represent the decision to protect the crop using partial budget analysis. This allows us to capture key properties of BW control strategies, while accounting for uncertainty about pest infestation pressure, control effectiveness and cotton yield and price. Our results indicate that proactive pest management is more efficient than reactive control given the current BW infestation pressure. However, farmers may prefer the reactive strategy, since they have experienced seasons with low infestation pressure where no insecticide applications were required. The proactive strategy, in contrast, requires scheduled pesticide applications in all years. Results show that in seasons with high infestation pressure the expected revenues of the reactive strategy tend to decrease, mainly because more spray applications are required when fields are heavily infested by the weevil. Value of information analysis revealed that uncertainties related to the start of the infestation, loss damage rate and attainable yield have the greatest influence on the decision recommendation for crop protection. Narrowing these key knowledge gaps may offer additional clarity on the performance of the current management strategies and provide guidance for the development of strategies to reduce insecticide use. This is particularly important for the promotion of the proactive strategy, which, under the current infestation pressure, has potential to reduce insecticide use. While economic injury levels can only be applied to responsive measures, our approach of partial budget analysis under uncertainty allows us to assess and compare both responsive and preventive measures in the same methodological framework. This framework can be extended to non-pesticide control measures.
\end{abstract}

Keywords Decision analysis · Pest management $\cdot$ Control strategies $\cdot$ Boll weevil $\cdot$ Partial budget analysis

Communicated by Cesar Rodriguez-Saona.

Oscar Burbano-Figueroa

burbano.figueroa1@gmail.com

Alexandra Sierra-Monroy

jaalexandrasierramonroy@gmail.com

Cory Whitney

cory.whitney@uni-bonn.de

Christian Borgemeister

cb@uni-bonn.de

Eike Luedeling

luedeling@uni-bonn.de
1 Center for Development Research (ZEF), University of Bonn, Genscherallee 3, 53113 Bonn, Germany

2 Turipaná Research Center, Corporación Colombiana de Investigaciones Agropecuarias (AGROSAVIA), Vía Montería - Cereté Km 13, 230558 Cereté, Córdoba, Colombia

3 Horticultural Sciences, Institute of Crop Science and Resource Conservation (INRES), University of Bonn, Auf dem Hügel 6, 53121 Bonn, Germany 


\section{Key message}

- Decision making in pest management is commonly addressed under assumptions of certainty and correlation between the pest presence and the expected crop damage and loss. We provide a methodological framework for the assessment of pest management strategies at farm scale using a decision analysis approach that is able to address this shortcoming of previous methods.

- We present a decision analysis approach for assessment of pest management strategies in the framework of yield gaps.

- We assessed control strategies used by cotton farmers for the control of the boll weevil and identified the most efficient option and the main sources of uncertainty related to the strategy choice.

- Decision analysis provides a robust methodological framework for the description and assessment of pest control strategies at farm scale. This approach can be applied in research settings of limited resources and it can effectively elicit and incorporate knowledge from farmers and other stakeholders.

\section{Introduction}

Pest management decision making is commonly addressed using economic decision levels such as economic injury levels (EILs) or marginal utility approximations. The EIL is defined as "the lowest population density that will cause economic damage" (Stern et al. 1959). It is used as a framework for supporting decision-making strategies at farm scale, considering a one-season planning horizon. EIL decision making is responsive rather than preventive. It is well suited for the dynamics of occasionally occurring pests, where pesticides can be applied based on prior scouting and assessment. Marginal utility analysis aims to maximize profits related to the control strategy. It is described by a utility function, where an increase in profits is expected for each monetary unit invested to protect the crop (Pedigo et al. 1986). These approaches to pest control decision making are based on assumptions of certainty (Pedigo et al. 1986).

However, decision making in pest management (similar to other problems in agricultural production) is a challenging task, given that many aspects of pest dynamics and control effectiveness are uncertain. For instance, decisions on prophylactic pesticide applications are usually taken without evidence of pest presence in the field and without estimations of the expected damage caused by the pest, the efficiency of the pesticide or the future value of the crop losses. Such preventive actions cannot be assessed using an economic threshold, because they are not closely correlated with pest density. As they involve considerable uncertainty, they also cannot be assessed using a deterministic marginal analysis. These challenges of common pest management decision frameworks can be resolved using decision analysis methodologies (Mumford and Norton 1984).

Pest management at farm scale is a chain of actions that are repeated season after season. As a recurrent affair, it is represented as a cyclical decision-making process. Synthesizing previous work (Norton 1976; Anderson et al. 1977; Mumford and Norton 1984; Waibel 1986; Pedigo et al. 1986), the pest control decision cycle during a cropping season can be described as follows (Fig. 1.):

1. Expected occurrence of a pest (or pest identification if it is a new pest)

2. Decision to protect the crop. A decision to protect or not to protect the crop against a specific pest based on assumptions related with the market value of the crop, the current pest infestation pressure, the expected pest infestation levels and the expected severity of the pestrelated losses (the perceived states of the system). Also referred to as the states of nature, the states of the decision maker's world or scenarios.

3. Execution of the control strategy. Once the decision maker has decided to act, she/he will usually apply a previously implemented control strategy. The conventional response of a decision maker in a management situation is to focus on the implementation of a historically well-informed practice (Parma and NCEAS Working Group on Population Management 1998; Shea et al. 2002). Each control strategy includes additional tactical and operational decisions mainly related to availability of physical resources (e.g., based on insecticide availability on local markets, or the availability of resistant cultivars) and financial resources. All strategies strive to keep pest populations under control. Strategic actions are mutually exclusive (discrete actions).

4. Forecast. All control strategies include a tactic for risk assessment based on monitoring or forecasting (including a mental model of farmers for signal detection or triggering of the response) of the infestation levels.

5. Implementation of control tactics. Control tactics are executed iteratively in response to perceived changes in pest infestation levels determining the economic/environmental consequences of the control strategy.

6. Outcome assessment. Benefits and effectiveness of the control strategy are judged on the basis of the perceived infestation level and compared with outcomes observed on other farms. 


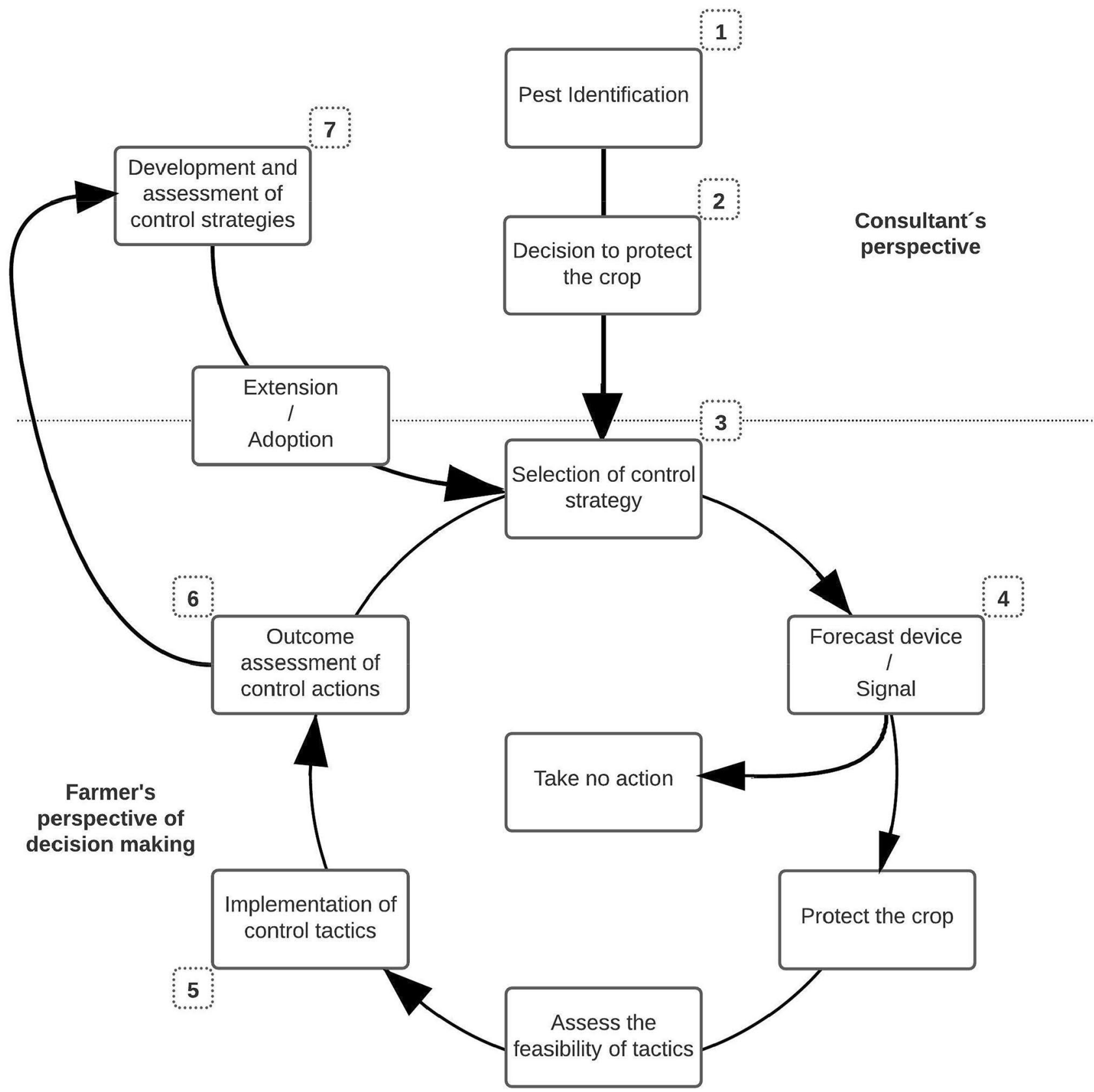

Fig. 1 Decision making under uncertainty in pest management represented as a cyclical process. Farmers and consultants have different perspectives about the decision-making process. Farmers tend to implement control strategies based on the "success" of previous experiences, while consultants have a meta-perspective that allows them

7. Development and assessment of control strategies. New information about pest management tactics and operations can also be provided by other stakeholders, such as researchers or crop advisors. Usually, control strategies implemented by farmers are not updated in these seasonal cycles and can only be challenged by active learning. Active learning is the goal of initiatives involved in to assess the current strategies and develop new ones. All control strategies are based on a forecast device or signal that farmers use to trigger the protection tactics. Control strategies are discrete alternatives that are not used interchangeably by farmers, and they can only be compared to the baseline scenario of "take no action" the adoption of new technologies by farmers (usually called extension services), and it requires the allocation of financial resources. Research and extension can provide a wide set of control strategies, identify relevant uncertainties and improve the decision rules that farmers employ in their decision-making process (Shea et al. 2002) 
The second (state of the system) and third (control actions) elements of the decision cycle are the determinants of the fourth element, the expected outcomes of the strategy. These are the main elements of the farmers' decision on whether to protect the crop. This decision is represented as a utility function using partial budgeting analysis (marginal function). The expected revenues at different levels of infestation in the case of "take no action" (let the invasion run its course) can be estimated from untreated plots of field trials or historical data, or elicited from experts. The crop losses resulting from these infestation events represent the upper limit of the returns of any crop protection strategy. How much of this "potential loss" can be prevented will depend on the effectiveness of the existing control strategies (Mumford and Norton 1984; Waibel 1986). "Take no action" is the initial state of the system (before the intervention). It provides a baseline for the comparison of the control actions under uncertain pest infestation levels (Moore et al. 2011). As the economic outcome (return) of each control strategy changes at different pest infestation levels and crop growth stages, strategy comparisons require a representation of these combinations. The best overall strategy is the one able to provide the best economic results in the majority of these combinations (Waibel 1986). This representation of the decision cycle describes the role of the farmers as managers (farmers as decision makers) and their preference for a specific strategy based on their risk perception and individual assessment of the economic consequences.

The sixth element introduces new information to the decision cycle, or comparison of the discrete actions used for pest control. These comparisons are not in the realm of the farmer's decision-making perspective, but within the scope of services provided by consultants. Consultants is a broad term for all stakeholders that are linked to the pest management process in a capacity that allows them to conduct "experiments" or do research (surveys, data analysis and interpretation, comparison of control strategies, forecasts or technical advice). The additional knowledge provided by these consultants (the consultant's perspective) can update the current beliefs of the farmers about pest control (extension services).

We use this framework to understand the control of the boll weevil (BW) (Anthonomus grandis grandis Boheman [Col.: Curculionidae]) at farm scale in the Colombian Caribbean. This investigation was framed as a decision analysis under uncertainty, undertaken to assess the benefits and uncertainties of the control strategies implemented in the Colombian Caribbean. The identification of uncertainties involved in these control strategies will allow farmers and consultants to explore how these strategies can be improved. Additionally, we compare the performance of the control options, in order to estimate which strategy has the greatest potential to reduce pesticide use (while providing similar economic benefits). Options with reduced use of pesticides are preferred because the long-term objective is the development of an integrated pest management program (IPM) for this pest.

To accomplish this goal, we implemented several decision analysis concepts, procedures and tools, drawing from Agricultural Decision Analysis (ADA) (Anderson et al. 1977) and Applied Information Economics (AIE) (Hubbard 2014). We used the framework provided by decisionSupport, an $\mathrm{R}$ package that facilitates decision analysis (Luedeling et al. 2021). Expert elicitation was used to provide input to the model, including uncertainties related with pest infestation levels. A probabilistic simulation based on the Monte Carlo method was used to project the outcomes of each strategy given the current pest infestation distribution. We calculated the value of information to identify decision-specific knowledge gaps of each control strategy that should be addressed by additional research (Koops 2004). Finally, given that we are comparing the outcomes of discrete strategies (actions), we used Stochastic Dominance (SD) as a measure of their efficiency. SD allows assessing risk when it is impossible to elicit utility functions for the decision makers involved (Gandhi et al. 1981; Levy 2016; Genest et al. 2016; Wu et al. 2017). This approach provides support for the decisionmaking process of farmers and identifies knowledge gaps that can be considered for further research by consultants.

\section{Materials and methods}

\section{Study background}

Boll weevil (BW) is considered the most problematic pest of upland cotton in Colombia. The weevil arrived in South America around the middle of the twentieth century, starting with two introductions via Venezuela (1949, Tocoron) and Colombia (1951, Cartagena), and colonized the entire Caribbean Plains within 5 years (Sierra-Monroy and Burbano-Figueroa 2020). Currently, BW is endemic in the dry and wet savannas of the Caribbean Plains causing seedcotton yield losses estimated between 250 and $500 \mathrm{~kg} / \mathrm{ha}$ and management costs of up to $10 \%$ of the total production costs (CONALGODÓN et al. 2008; Ñañez 2012; OsorioAlmanza et al. 2018). At farm level, BW is mainly controlled using synthetic insecticides, which increase crop production costs and cause undesirable environmental impacts (ICA 2010). Over the past 15 years, cotton fields in Colombia were sprayed seven times per year, on average, against cotton pests, with $70 \%$ of these applications aiming to control BW (Ñañez 2012).

Two strategic options based on synthetic insecticides are currently implemented to control BW at farm level in the Colombian Caribbean: (1) proactive: early insecticide 
applications to eliminate the BW founder population arriving to the cotton crops early in the season, and (2) reactive: late insecticide applications to reduce population growth rates and decrease yield losses associated with BW invasion of the crop (Fig. 2) (Burbano-Figueroa et al. 2019). In the proactive strategy, insecticide sprays are applied to control the early arrival of the weevils to the field, which occurs during squaring (cotton bud break stage of development prior to bloom). These applications target the migrating females (coming from the refuges) ready for oviposition on the first squares and for the establishment of the founder population in the crop. Reactive management of BW, in contrast, is based on a series of focused insecticide applications that are triggered by the observation of BW aggregation spots and aim to disrupt the established population (Gómez Lopez 1981; Yepes Rodriguez 1997). If this population is not completely eliminated, subsequent weekly field sprays are applied until the population is eliminated or the crop reaches maturity. Farmers use on average 7-10 applications per crop season, and up to 15 sprays may be required for fields exposed to high BW infestation levels (Grandett-Martinez et al. 2003; Osorio-Almanza et al. 2018). Most BW management actions applied by farmers in the Colombian Caribbean rely heavily on the reactive strategy to contain weevil pest populations (Burbano-Figueroa et al. 2019).

\section{Data source}

In our previous work, we developed a conceptual model and identified variables and parameters associated with the management of BW based on information derived from focus group discussions and semi-structured interviews with knowledge holders (Burbano-Figueroa et al. 2019). The core group of experts consisted of a cotton plant physiologist, a cotton breeder, four entomologists (three with expertise in BW management, and one with expertise in insect ecology) and five crop advisors and/or farmers (who are responsible for a large share of the entire cotton producing area of the Colombian Caribbean region). Based on their inputs, we identified two scales that deal with critical issues for BW management: (1) pest management at farm scale and (2) issues related with the regional suppression program (Burbano-Figueroa et al. 2019).

In the present work we follow up on these findings, exploring in more detail the economic implications of the strategic scenarios used for BW management at farm scale. Besides using data from Burbano-Figueroa et al. (2019), we gathered additional information via unstructured interviews and included related technical reports, which were collected from the Biblioteca Agropecuaria de Colombia (BAC; https://repository.agrosavia.co/), a local repository, and from personal libraries of researchers associated with Turipaná Research Center-AGROSAVIA.

We received additional feedback from the Regional Cotton Committee (CRA) headquartered at the municipality of Cereté, Cordoba. CRA is a local initiative of the Sinú Valley farmers with monthly meetings for discussing, proposing and evaluating all actions related to the cotton value chain in the valley. Focus group discussions, interviews and feedback were mainly coordinated with the support of this committee. We distributed a Spanish version of this document to CRA members and their related institutions to elicit feedback.
Fig. 2 Description of strategies used for the control of the boll weevil (Anthonomus grandis grandis) in the Colombian Caribbean. The description of cotton phenology is based on field assays of several cultivars planted in the Sinú Valley of the Colombian Caribbean (Burbano-Figueroa and Montes-Mercado 2019). Arrows with lighter colors represent additional insecticide applications for controlling remnant BW populations that were not eliminated in the first control operations

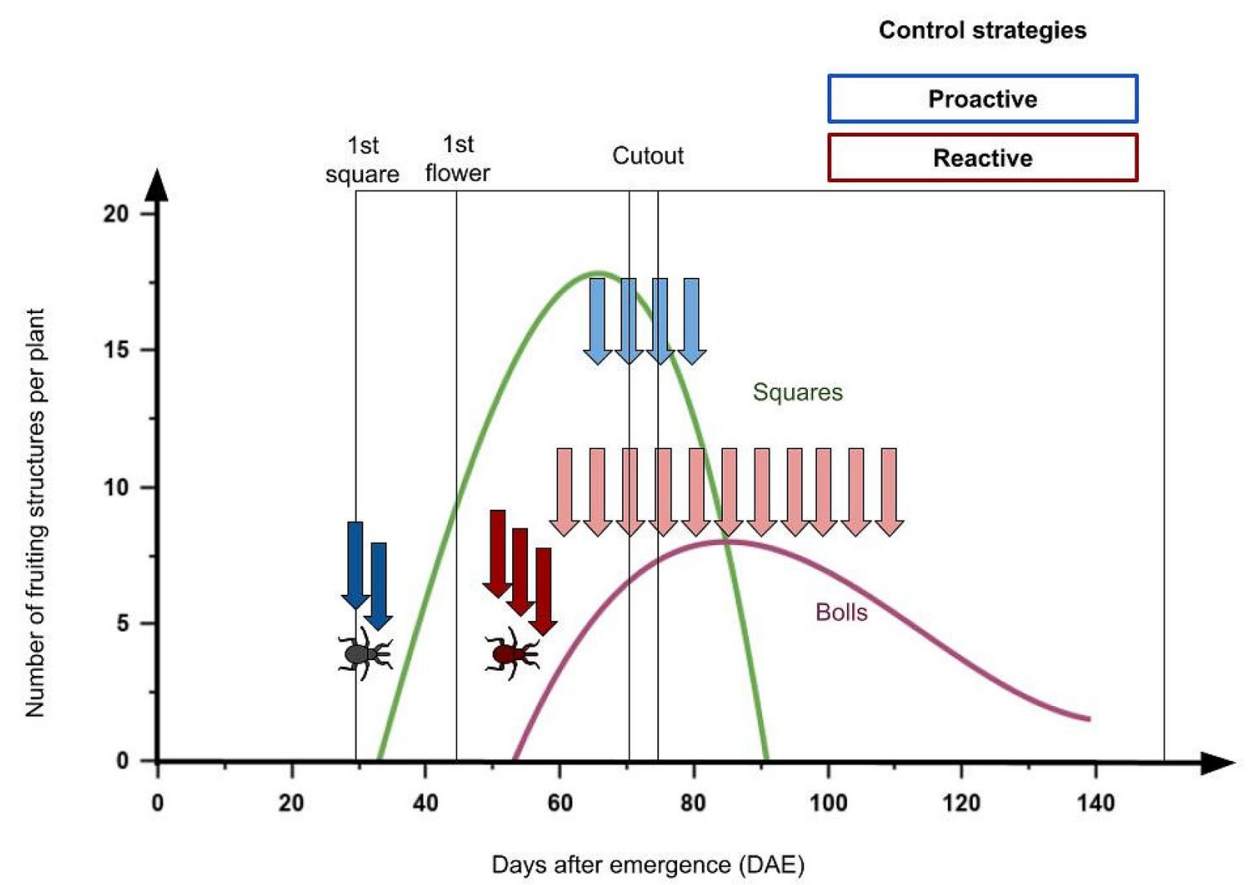


Quantitative descriptions of parameters and variable ranges were estimated based on available technical reports or from calibrated experts. We elicited quantitative information after experts were subjected to a calibration training procedure. Training consisted of increasing the experts' awareness of concepts of probability and instruction in techniques to produce accurate estimates of confidence intervals for unknown variables that reflect the estimator's level of uncertainty (Hubbard 2014; Hubbard and Millar 2014; Luedeling and De Leeuw 2014; Luedeling et al. 2014, 2015; Yigzaw et al. 2019). The resulting subjective probability distributions constitute explicit representations of the state of certainty about events or states of nature (the states of the decision maker's world) (Anderson et al. 1977).

\section{Decision framework for assessing BW control strategies}

The decision to protect the cotton crop is supported by comparing the expected return on investments in pest control with the alternative option of not controlling the pest. Farmers who choose not to apply insecticides may suffer yield losses and consequently economic losses from insect damage. However, if they choose to protect the crop, they may spend more than the value of the crop saved, which would lead to a net economic loss. Farmers who decide not to control a pest may suffer considerable losses in years of high pest infestation (Norton 1976; Mumford and Norton 1984; Waibel 1986; Pedigo et al. 1986). In this decision model framework, we assessed the effect of two strategies for BW control using the baseline scenario of "take no action" against BW.

The proactive strategy aims to avoid colonization of the first squares by the migrant BW population and to generally limit the extent of early colonization of the crop. This requires early applications of insecticides even if the weevils are not detected during scouting. This strategy results in the contingency of fixed cost for crop protection (insurance), which may be considered wasteful in years or scenarios with no pest occurrence. In years of high infestation, additional insecticide applications are required for protecting the new young squares until the fruiting cutout (cessation of square production). After this point, the majority of the yield share (in terms of squares) is protected and the later-arriving BW populations have a limited supply of food as the squares develop into bolls. Bolls can be attacked by the weevils only when the crop is heavily infested as a result of early colonization.

In the reactive strategy, farmers scout for BW aggregation spots, which are heavily treated to control the colonizing population. Once BW aggregation spots are identified, these are individually sprayed over the following weeks. Several applications are required to eliminate individuals of different ages emerging from the squares. This strategy is not completely effective, and in heavily infested fields farmers must spray insecticides over the entire field several times a week. In this strategy, BW is only detected when it has already colonized the crop.

The "take no action" strategy is not purposely used in the Sinú Valley, but it is commonly implemented in marginal cotton areas in the Upper Magdalena Valley. In the Sinú Valley, this strategy is reported to occur by default in years of low BW infestation in isolated cotton fields that are managed under the reactive strategy. We use "take no action" as the baseline for the comparison of management strategies. Under the assumption of no action, if a migrant BW population arrives at the crop during the squaring stage, it will consume all the available squares and reproduce freely, causing high or complete losses. Such BW infestation events constitute the scenarios where control strategies would generate the maximum possible benefits. How much of this "potential loss" can be prevented will depend on the effectiveness of the implemented control strategy. In terms of yield, this effectiveness is represented by the avoided yield losses. In the framework of yield gaps, the "take no action" strategy represents the "reduced yield," the observed yield after accounting for losses related to reducing factors, in this case the damage associated with BW. The yield obtained after the implementation of pest control is the actual yield. It is not uncommon that taking no action is a profitable option, especially in scenarios where the pest density is very low and the associated damage is economically tolerable (the economic damage threshold).

\section{Model conceptualization and simulation}

The decision model for the control strategies contains two subsystems that were used to estimate the net revenues of $\mathrm{BW}$ control measures:

1. A biological subsystem that describes attainable cotton yield, pest infestation levels and the interaction between cotton plants and the pest.

2. An economic subsystem represented by a production function that emphasizes the changes in revenue and expenses that result from executing a specific pest control action. Production functions are represented by partial budget analysis (Kay et al. 2016, 2019). Partial budget analysis describes the additional costs of operation associated with the decision to use or not use a treatment (action or intervention) and the relationship between these costs and additional benefits (Perrin et al. 1983; CIMMYT 1988). The production function used here is a generalization of the economic injury level concept and it is also linked to the concept of production situations that define yield levels. In this framework, 
the production function also illustrates the investment required for closing the current yield gaps for a specific crop facing one or multiple (biological) limiting factors (Fig. 3).

The net revenue $\mathrm{NR}_{j}$ is defined as a function of the attainable yield $Y_{w}$, losses caused by BW $L_{\mathrm{BW}}$, the effectiveness of the control strategies $E_{j}$, the cotton output price $p_{Y}$ and the control costs $C_{j}$ of the tactic $j$ (modified from (Pemsl and Waibel 2007) (Eq. 1)

$\mathrm{NR}_{j}=f\left(Y w, L_{\mathrm{BW}}, E_{j}, C_{j}, p_{Y}\right)$

The net revenue of a pest control measure is estimated as the additional net revenue relative to the baseline of no control. It is calculated from estimations of the benefits and costs of each pest control measure. For each control strategy, the benefit is defined as the avoided yield loss for a particular pest control measure.
The difference between the actual yield $Y_{a}$ (Eq. 2) and the yield reduced by the pest $Y_{\mathrm{BW}}$ (Eq. 3) was used to estimate the avoided yield loss for each strategy (Eq. 4).

$Y_{a}=Y_{w} *\left(1-L_{B W} *\left(1-E_{j}\right)\right)$

$Y_{\mathrm{BW}}=Y_{w} *\left(1-L_{\mathrm{BW}}\right)$

$\mathrm{AYL}_{j}=Y_{a}-Y_{\mathrm{BW}}$

Finally, the net revenue for each control tactic was estimated as the difference between the value of the avoided yield loss and the cost of the control strategies:

$\mathrm{NR}=\mathrm{AYL}_{j} * p_{j}-C_{j}$

Our decision model is drafted within the framework of yield gaps and describes a yield-reducing factor, and the gap between attainable yield and reduced yield. Cotton crops in the Colombian Caribbean are rainfed and highly variable. We estimate the distribution of attainable cotton yield

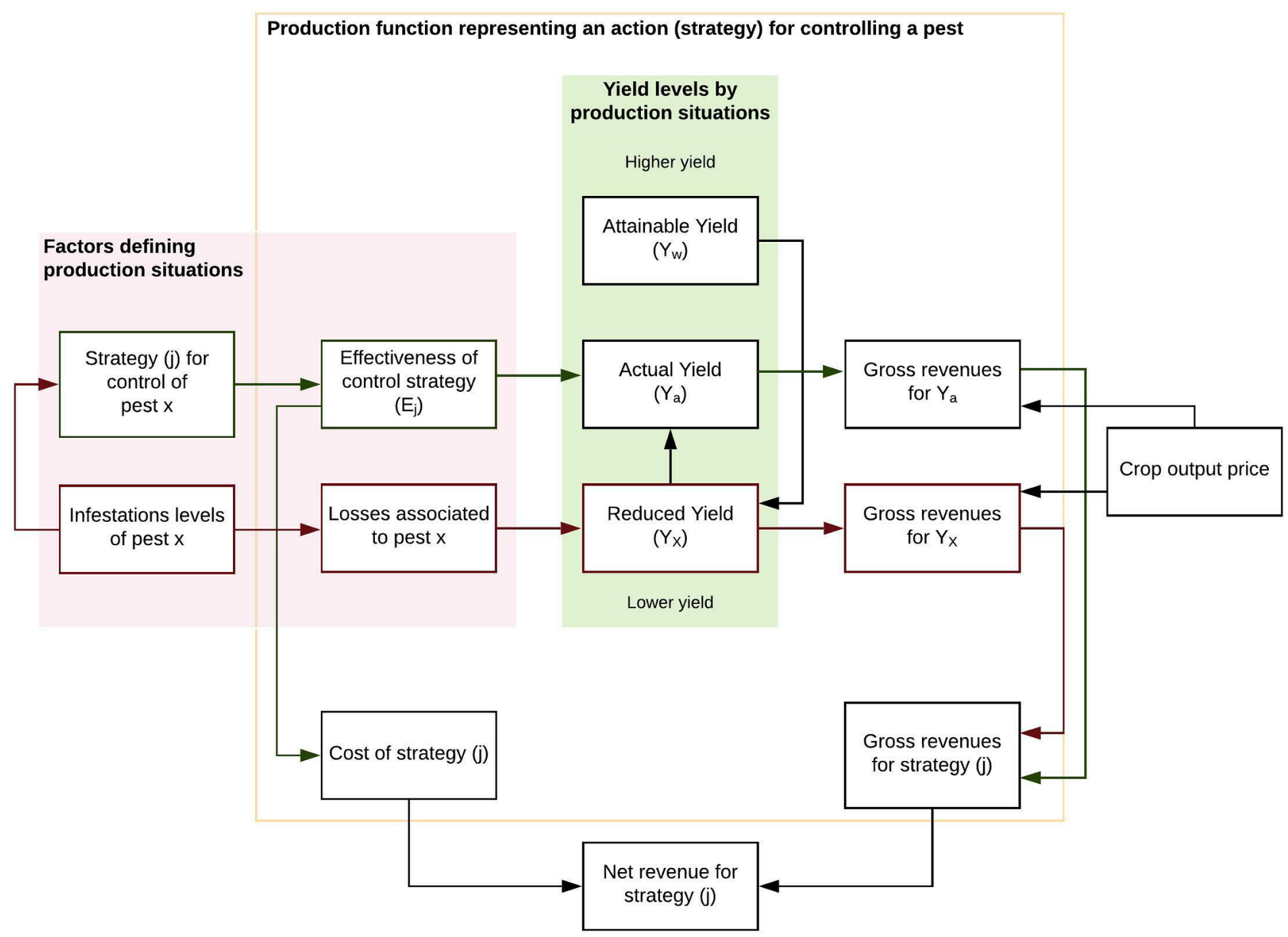

Fig. 3 Structure of the production function representing an action (strategy) for controlling a pest in a rainfed production system 
using field data (Moreno-Moran and Burbano-Figueroa 2017; Agronet 2018) and reports from farmers. The crop infestation by BW was estimated as a linear function of the percentage of infected squares before the opening of the first boll (80 days after emergence; DAE) and the density of the migrating BW populations at the start of the fruiting period. The level of expected crop infestation was used to estimate the expected yield losses caused by BW. The required number of pesticide applications was estimated as a function of the crop infestation levels (Grandett-Martinez et al. 2003).

\section{Probabilistic simulation}

All variables described in the stated equations are of stochastic nature, i.e., their precise values in any given year cannot be precisely predicted. To address the uncertainty that is inherent in the data, we assessed the profitability of the control options using a Monte Carlo simulation. Plausible values for all variables included in this model were defined as probability distributions, defined by distribution shape and estimated confidence intervals (provided in supplementary materials). From these distributions for all variables, we drew 10,000 sets of random samples, which were used as model inputs to compute 10,000 plausible values for the new revenue of each tactic.

To determine the sensitivity of the net revenue to the explanatory variables, we conducted Projection to Latent Structures (PLS) regression on the outputs of the Monte Carlo simulation, relating outcome variables to all uncertain model inputs. The selection of the most sensitive variables was done based on variable importance in the projection (VIP) calculation. The VIP score measures the influence of an individual input variable on the revenue (outcome) of the control strategies. Variables with a VIP score $>0.8$ were considered as influential variables. For these variables, we also determined whether they had a positive or negative influence on projected revenues.

We then applied value of information analysis to determine whether collecting additional information on a certain input variable would be warranted for adding certainty to the decision on which option is preferable. We quantified the value of information by computing the expected value of perfect information (EVPI). The EVPI represents the monetary value that would hypothetically be worth investing in order to completely eliminate uncertainty on specific variables in the decision-making process (Hubbard 2014). The EVPI can guide and underpin research priorities, especially in an environment with limited funding for additional data collection (Luedeling et al. 2015; Whitney et al. 2017). We used the EVPI to provide guidance to local research efforts for reducing the uncertainties of the implemented strategies for controlling BW (box 6 in the decision cycle). If one of these control strategies shows competitive revenues and has the potential to reduce use of insecticides, reducing associated uncertainties can facilitate adoption by farmers.

\section{Ranking BW control strategies with stochastic outcomes}

For many decisions, decision analysis produces outcome forecasts where the distributions of plausible outcomes for the different options differ clearly enough to allow identifying the preferable course of action. Yet this is not always the case, and many analyses produce outcome distributions with strong overlap. Often such outputs also feature different distribution shapes, which complicates the decision on which decision option is preferable. The standard procedure in decision analysis indicates that at this point, additional information should be collected on high-value variables, but many decision makers have no resources for such collection, and for many uncertainties, especially in highly stochastic contexts such as pest control, meaningful gains in certainty may be impossible. Decision analysis procedures would thus greatly benefit from improved mechanisms to identify a preferable option even in a context of high residual uncertainty. So far, this initial call has usually been based on the concept of expected value of the outcome variable (Luedeling et al. 2015; Wafula et al. 2018; Whitney et al. 2017; Ruett et al. 2020), but this concept is ignorant of decision makers' attitude toward risk, which features prominently in many decision-making processes. To add nuance to the initial evaluation on which decision option should be preferred, we ranked the outcomes of the strategies using stochastic dominance. Stochastic dominance describes the relationship between the decision maker's attitude toward risks and the ranking of probabilistic outcomes using stochastic orderings.

\section{Stochastic ordering and preferences of the decision makers}

Stochastic ordering is a concept of probability theory that refers to the probabilistic comparisons of random variables, i.e., any binary relation in a set of probability distributions. Two main stochastic orderings or comparisons are used with the aim to identify differences in a pair of probability distributions. In the first comparison, one distribution in some sense attaches greater probability to larger values than the other one does. If the pointwise values of one distribution are greater than the values of the other one, one of the two distributions is referred to as stochastically larger than the other one. This ranking of magnitude of distribution functions is also called strong, classical, usual or first stochastic ordering (Muller and Stoyan 2002; Shaked and Shanthikumar 2007; Whitt 2014).

A second comparison is that one distribution is more spread out or dispersed than the other. If two distributions 
have equal means, the distribution that is more narrowly distributed or whose values are concentrated is said to be stochastically less variable. This ranking of distribution dispersion is also called secondary stochastic ordering, or convex order, and it is a part of the inequality properties that describe distribution functions (Ross 1995; Muller and Stoyan 2002; Shaked and Shanthikumar 2007).

These stochastic orderings are associated with subjective preferences and risk attitudes of the decision maker for options with increasing expectation of beneficial outcomes (Hadar et al. 1969; Rothschild and Stiglitz 1970; Levy 2016). First, any decision maker will prefer an action whose outcome is stochastically larger in comparison with the outcome of alternative options because everyone prefers more to less. This rule about a decision maker's preference for choices with higher stochastic magnitude is called firstorder stochastic dominance (FSD) (Rothschild and Stiglitz 1970; Levy 2016).

The FSD does not always hold for all values of the probabilistic distribution (partial order). In this case, the choice with the outcome that provides higher mean and less dispersion is considered more beneficial (higher expectations) and less risky. A risk-averse decision maker will prefer expected outcomes of this type. This rule of preference is called second-order stochastic dominance (SSD) (Rothschild and Stiglitz 1970; Levy 2016).

For the SSD, there is an alternative scenario. The choice with the higher mean can have a wider distribution and thus be perceived as a risky option. A risk-averse decision maker does not want the heavier losses associated with a wider distribution. However, an option that provides higher benefits and higher risks is preferred by risk seekers. This preference is called inverse second-order stochastic dominance (ISSD) (Aaberge et al. 2013; Wu et al. 2017; Spiegel et al. 2018).

\section{Stochastic dominance assessment}

Stochastic dominance rules are commonly represented and analyzed using cumulative distribution functions (CDFs) (Fig. 4). We plotted the outcomes of the assessed strategies as CDFs with the aim to identify the prevailing dominance between these strategies and the implications for the riskattitude of the decision maker.

Additionally, we note here that when distributions are derived from a Monte Carlo analysis, analysts may also consider basing their evaluation on the distribution of differences between options among the model runs rather than on separate outcome projections for each option (as in Ruett et al. 2020). This pointwise difference of binary relations between probability distributions is a numerical (monetary in our case) approximation for quantifying the magnitude of the dominance between distributions regardless of the stochastic orderings or dominance rules. Stochastic orderings (and by extension dominance rules) are partial orders that represent relations in a continuous space that at least in magnitude can be captured by our proposed pointwise difference. Additionally this assessment can facilitate the discrimination between FSD and SSD. If during this assessment, all values are positive we have an FSD. Alternatively, if not all values are positive, we know that an SSD prevails and the representation of the CDFs will clarify the nature of this second-order dominance.

\section{Software and analytical tools}

Model code and analysis were implemented in the R programming language (R Core Team 2018). Monte Carlo simulations, PLS and EVPI analysis were developed with functions of the decisionSupport package (Luedeling et al. 2021). Supplementary files contain a description of $R$ code and model input as spreadsheet files.

\section{Results and discussion}

\section{Profitability of boll weevil control strategies}

Model simulations revealed wide ranges of net revenues for the control options used against BW (Fig. 5). The median net revenue of the proactive strategy was estimated at 916 thousand Colombian pesos (COP)/ha with $90 \%$ confidence that the actual value lay within the range of -136 to 3436 thousand COP/ha. The chance of negative revenues for this strategy was estimated at $24 \%$. The median net revenue of the reactive strategy was 745 thousand COP/ha with a $90 \%$ confidence range of -233 to 3090 thousand COP/ha. The chance of loss of the reactive strategy was $31 \%$. The assessed control strategies cannot be ranked using their means and variance because of considerable overlap in revenue distributions (i.e., they are not statistically different and the risks of losses are similar).

Proactive revenues are stochastically larger than reactive revenues for most of the distribution. The magnitude of this dominance has a median of 224 thousand COP/ha with a $90 \%$ confidence range of -100 to 808 thousand COP/ha (Fig. 6). Simulation results were plotted as cumulative distribution functions (CDF) and the control strategies ranked using the hierarchical rules of stochastic dominance (Leshno and Levy 2004; Wu et al. 2017; Jiang et al. 2018). The proactive strategy, the option with the higher mean, exhibits a wider dispersion than reactive control. Proactive dominates reactive management by ISSD, in consideration of its greater partial magnitude and wider dispersion (Fig. 7).

An alternative practical definition of dominance (or efficiency) that is used in partial budget analysis can help to clarify the advantages of the proactive strategy over the 

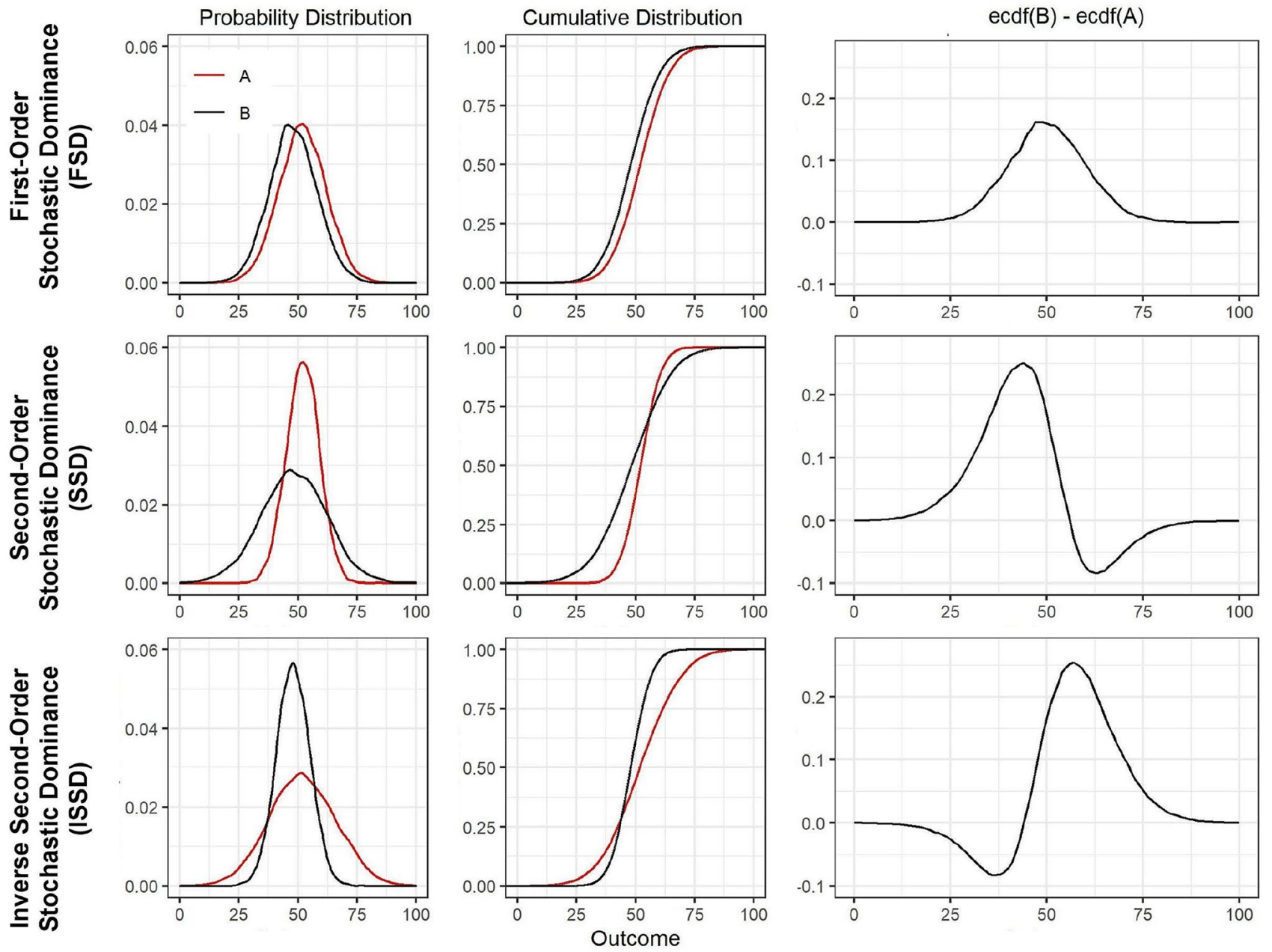

Fig. 4 Comparing two distributions, $\boldsymbol{A}$ (red) and $\boldsymbol{B}$ (black), using stochastic dominance rules. In all rows, $\boldsymbol{A}$ has a higher mean than $\boldsymbol{B}$, i.e., $\boldsymbol{A}$ is the dominant option. In the first row, $\boldsymbol{A}$ is stochastically larger than $\boldsymbol{B}$ (FSD), and it is preferred by all decision makers (everybody

reactive approach. For alternative actions with similar ranges of revenue distributions, the most efficient is the one with the lower cost or amount of input (Perrin et al. 1983; CIMMYT 1988). We extended such definition to insecticide use for providing a measure of the environmental and human health benefits of the proactive strategy. Figure 8 shows the distribution of cost and number of insecticide sprays for proactive and reactive strategies. Insecticide input (as cost or insecticide sprays) of the reactive strategy has a wider distribution than that of the proactive approach. The reactive strategy uses less insecticide than the proactive one in scenarios with no or low infestation, where insecticides are not applied. Higher inputs for the reactive strategy are expected in scenarios with large migrating BW populations. In these scenarios, crops are colonized early in the season, resulting in high infestation levels that require numerous insecticide sprays for effective control. On the other hand, a proactive wants more). In the middle row, $\boldsymbol{A}$ is less dispersed (less risky) than $\boldsymbol{B}$ (SSD), and it is preferred by risk-averse decision makers. In the third row, $\boldsymbol{A}$ is more dispersed than $\boldsymbol{B}$ (ISSD), and it is preferred by riskseeking decision makers

strategy is more effective in scenarios with large weevil populations. Insecticide sprays prevent early colonization of the crop and avoid the build-up of large weevil populations that can only occur before the cutout (when abundant squares are available). The proactive strategy is disadvantageous when no weevil arrives early to the field and insecticides are applied without need. However, this uncertainty can be eliminated or reduced with the use of the pheromone trap index (Rummel et al. 1980). This index can be used for estimating migrant population sizes during the squaring period and provide advice about the need for early insecticide sprays. Pheromone traps are already deployed in the Caribbean (ICA 2009), but the data collected are only available upon request and mainly used for postseason assessment.

Previous reports already indicated greater economic efficiency of proactive BW strategies compared with strategies based on scouting and damage thresholds (Ewig and 


\section{Outcome distribution Strategies $i \frac{1}{i}$ Proactive $\frac{i}{i}$ Reactive}

\section{Variable Importance}

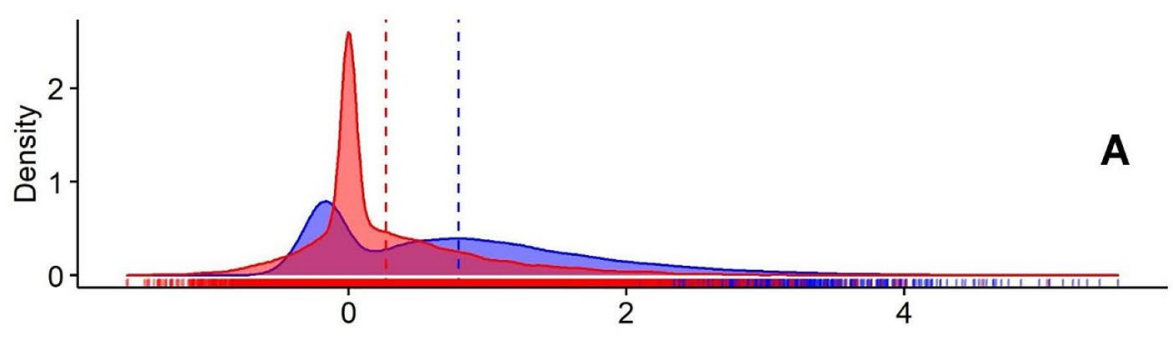

Net revenue for control strategies (COP million/ha)

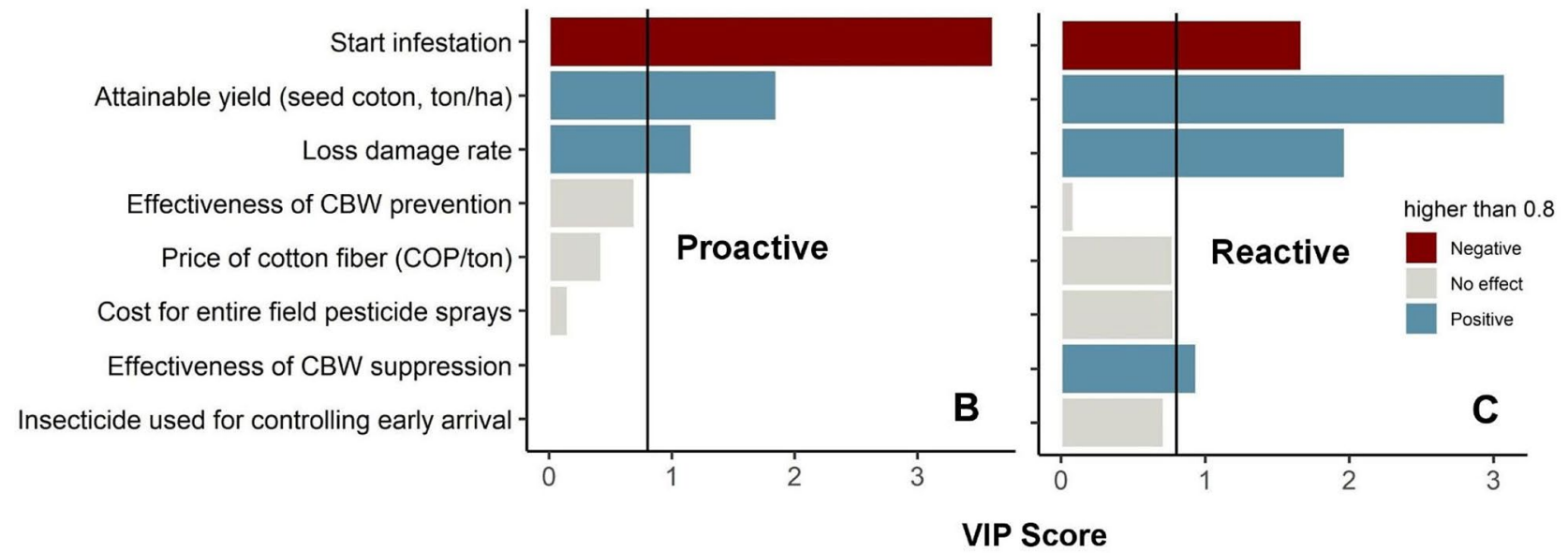

\section{Information Value}

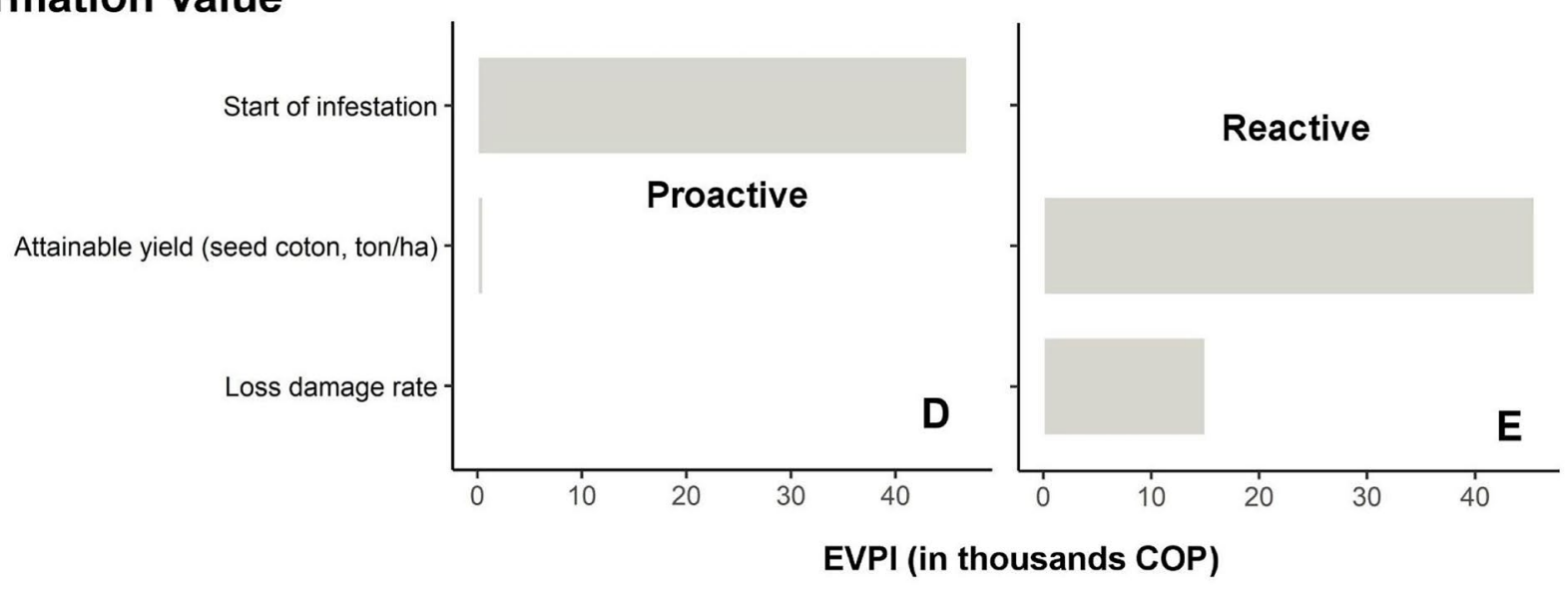

Fig. 5 Assessment of control strategies against the boll weevil in the Colombian Caribbean: projected outcome distributions of control strategies (a), important variables (determined by Projection to Latent Structures (PLS) regression; $\mathbf{b}$ and $\mathbf{c}$ ), and high-value variables (Expected Value of Perfect Information (EVPI); d and e). Manage-

Parencia 1949; Mistric and Covington 1968; Mistric and Mitchell 1968). Scouting and damage thresholds are part of the EIL philosophy, which posits that insecticides should only be sprayed when the pest population has reached a threshold (action threshold) that is expected to cause ment actions were assessed through Monte Carlo simulation based on 10,000 model runs. Vertical dashed lines in the outcome distributions show median values. All values are estimated in Colombian pesos (COP)

economic losses. However, some pests, including BW, can quickly build up large populations from only a few colonizing individuals. This rapid increase in pest incidence challenges the action threshold concept. Proactive BW strategies aim to avoid the colonization of the first cotton squares by 


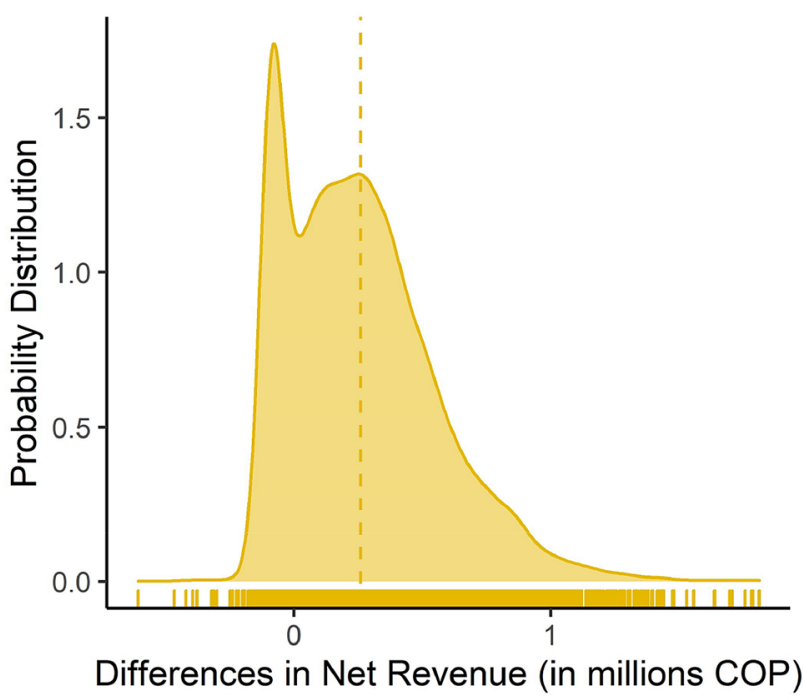

Fig. 6 Pointwise difference in net revenues of control strategies against the boll weevil in the Colombian Caribbean (Proactive minus reactive). Revenues are calculated in Colombian pesos (COP)

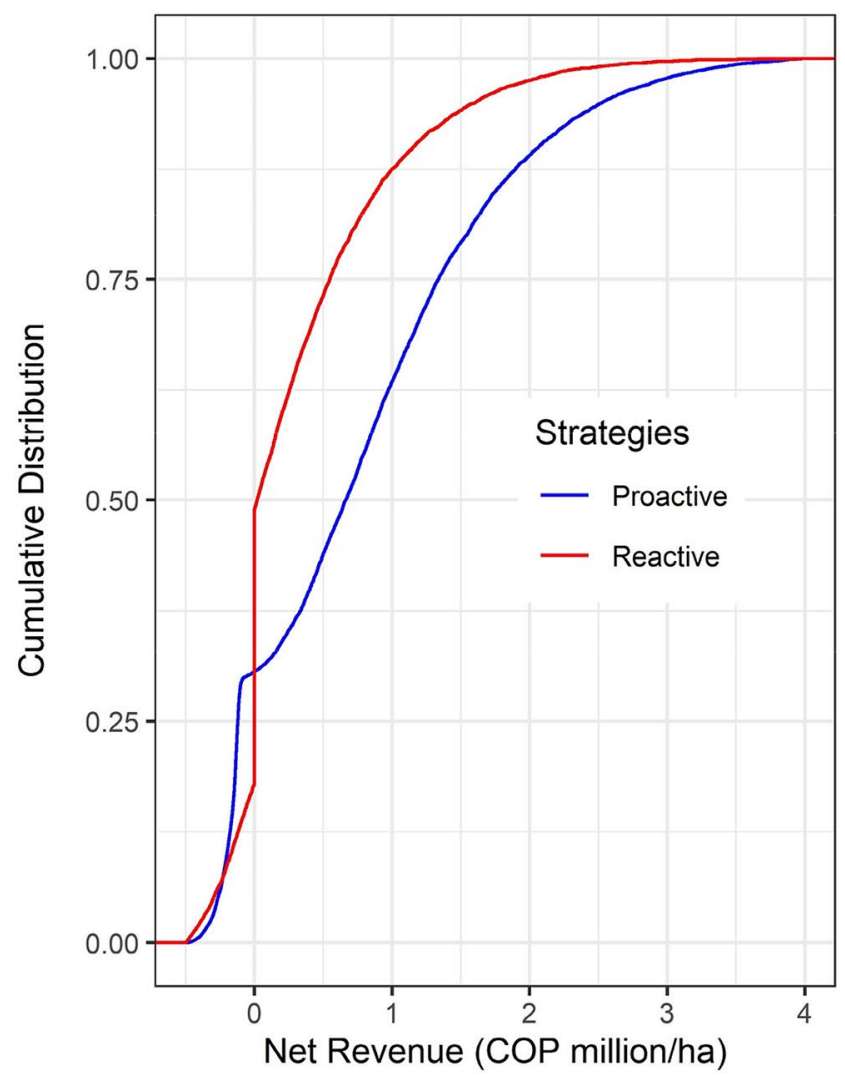

Fig. 7 Comparison of the net revenue distributions for strategies used to control the boll weevil. The cumulative distributions of proactive and reactive strategies cross each other, indicating a lack of firstorder stochastic dominance. Proactive exhibits net revenue values female weevils via insecticide applications just before the squares are large enough to sustain developing larvae. This makes it possible to control the maximum number of adults emerging from hibernation (or feeding on alternative hosts) before they can reproduce (Ewig and Parencia 1949; Mistric and Covington 1968; Mistric and Mitchell 1968; Hardee and Harris 2003). Control methods based on thresholds or monitoring allow establishment of nucleus populations that can grow rapidly, especially in warm regions such as the Colombian Caribbean, where temperature promotes fast weevil development during the entire season. Such populations can then easily reach sizes that require numerous insecticide applications.

Apart from the additional cost and insecticide consumption, the reactive strategy has an additional burden related with the regular scouting program. We tried to estimate the cost of these actions but the dominant perspective between farmers and crop advisors is that these actions do not create additional costs. The rationale for this perspective is that all crop advisors are contingent independent workers that are paid on a per-hectare basis for weekly inspections and recommendations. Scouting is one of the weekly activities

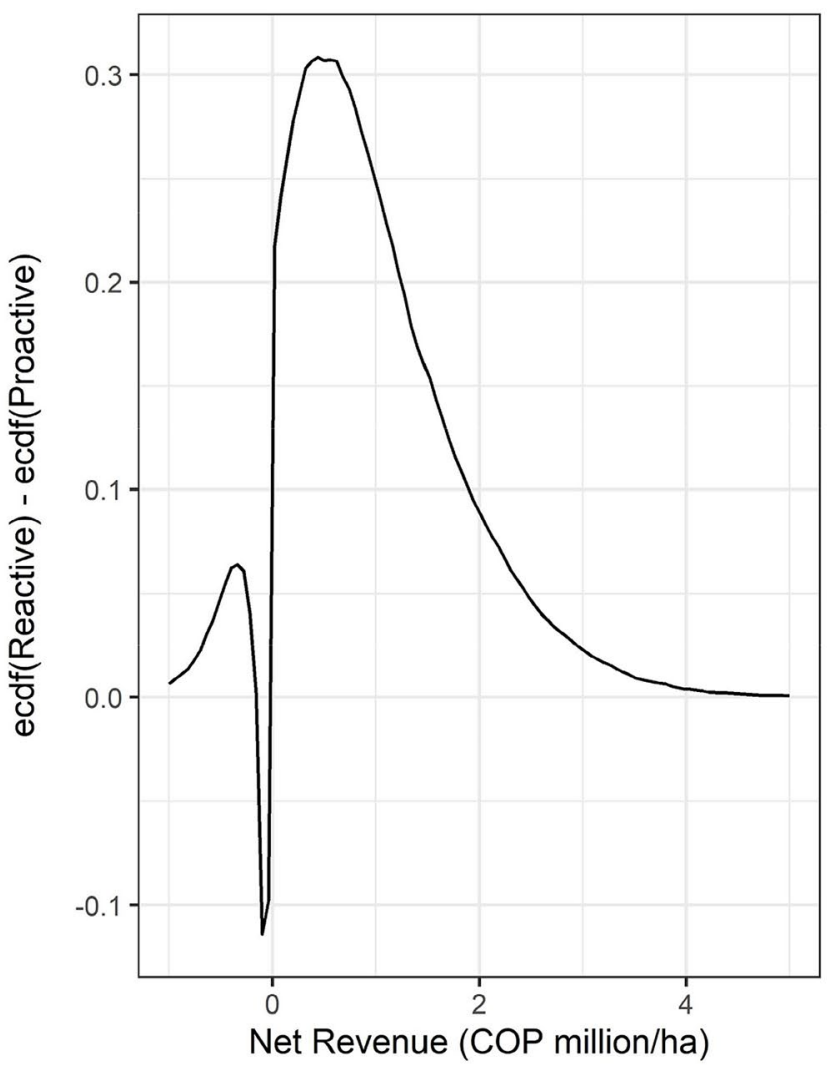

with a higher mean and wider distribution than reactive management (inverse second-order stochastic dominance). Revenues are calculated in Colombian pesos (COP) 


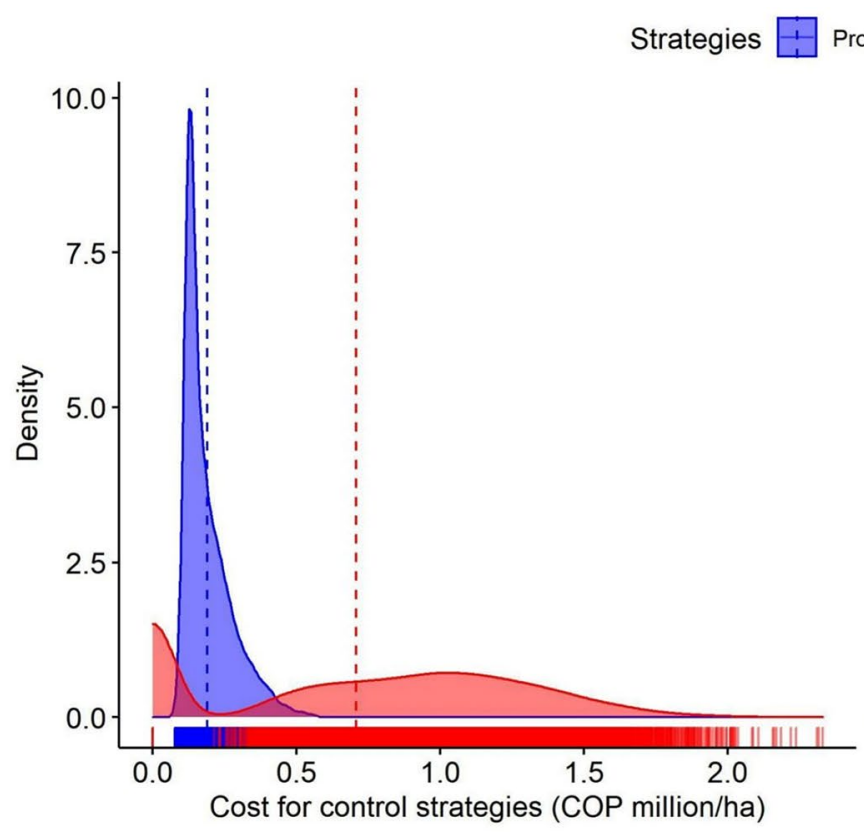

Fig. 8 Cost distribution and insecticide use for the strategies employed in the control of the boll weevil in the Colombian Caribbean. The number of entire-field applications is provided as a proxy for insecticide consumption. The most common insecticide used for

undertaken by crop advisors with the aim to provide recommendations. Even though it was not possible to translate this burden to economic cost, there is still a decision cost for the agent taking the decision. Decision cost is a term used to describe the overall costs related with the work done before the actual choice, which results in cognitive burden. This cost can be measured as time, money, anxiety, agitation, remorse and feelings of responsibility, guilt or shame that can be experienced by the decision-making agent (Sunstein and Ullmann-Margalit 1999). In comparison with the proactive approach, crop advisors (the decision-making agent in this case) using the reactive strategy have to invest more time and effort (decision cost) for providing recommendations for controlling the pest, which can result in poor planning and decision making for other decisions related with the management of the crop. On the other hand, crop advisors who use the proactive strategy have simple, clear and reliable rules for starting the insecticide sprays. This promotes predictability and minimizes the burden of subsequent decisions.

\section{Decision-relevant uncertainties and their value of information}

For both BW control strategies, VIP scores were fairly high for three variables: onset of cotton field infestation, loss damage rate and attainable yield (Fig. 5). Infestation onset and loss damage rate are used to estimate the risk of BW

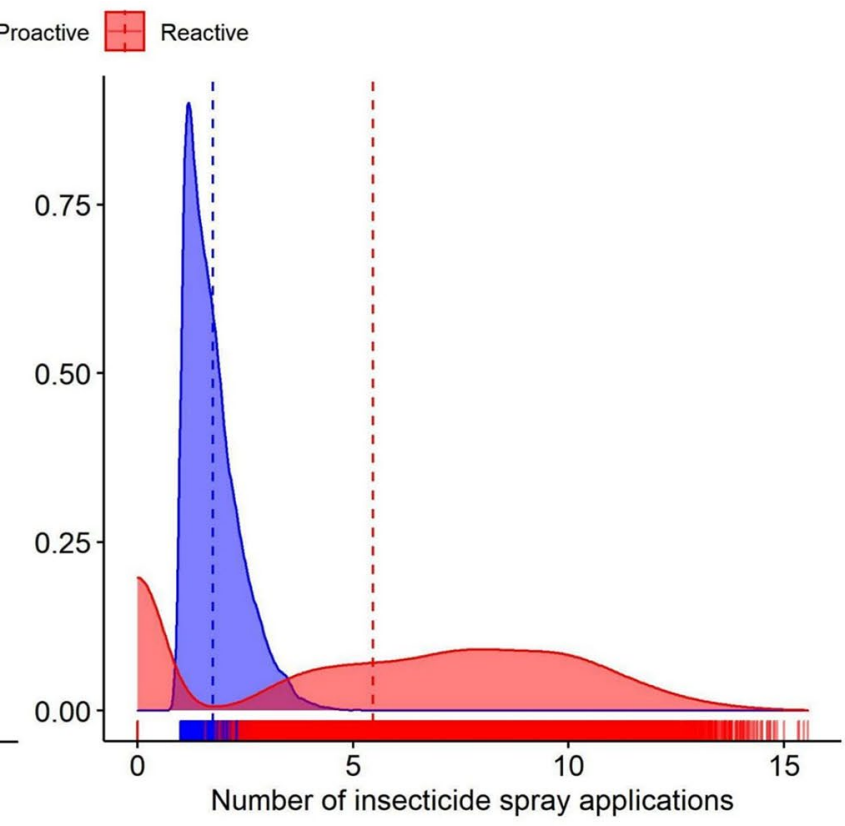

entire-field applications is fipronil (200-250 g/liter) with an application rate of $0.35-0.5 \mathrm{~L} / \mathrm{ha}$. In comparison with the reactive strategy, the proactive strategy has the potential to reduce insecticide consumption

colonization and the corresponding future losses. Proactive and reactive strategies use different approaches to assign values to these variables and to trigger control action against BW. Proactive strategies use prior probability distributions of the initial weevil infestation in order to forecast losses that justify scheduled application of pesticides. Reactive strategies do not use prior distributions of these variables but monitor damage in the cotton field to determine where pesticide application is justified.

Proactive strategies against BW use an assumption of early arrival of the weevil to the field as rationale for calendar applications of insecticides. In the Lower Rio Grande Valley of Texas (LRGVT), this pest was controlled by a set of proactive strategies that differed in the timing of the first spray. The standard proactive BW strategy was to apply insecticides during pinhead square formation (PHF) followed by up to 2 more applications in the following weeks. After this point, insecticide applications were triggered whenever $10 \%$ of randomly selected squares had oviposition punctures. This threshold is usually reached at the end of square production when bolls are the predominant fruiting stage (Mistric and Covington 1968; Heilman et al. 1979; Showler 2004; Showler and Robinson 2005). The strategy assumed that weevils were in the field before PHF. Ambiguous field results of this strategy fostered the development of a modified control strategy (Showler 2004, 2012). The early spraying of the alternative strategy was not triggered by the 
occurrence of PHF, but by the appearance of large squares (diameter of 5.5-8 $\mathrm{mm}$ ), which was followed by continuous application at 7 to 8 -d intervals while abundant large squares were still visible. This alternative strategy resulted in fewer infested squares and higher yields in comparison with spraying during the PHF phase (Showler and Robinson 2005). The two alternative triggering signals for the start of insecticide application in the proactive strategy used in the Colombian Caribbean resemble the triggering signals used in the LRGVT.

Monitoring based on aggregation spots (as practiced in the reactive strategy in Colombia) does not appear to be practiced at all in the LRGVT or other growing regions in the USA. This strategy was developed in Nicaragua and possibly introduced to Colombia in the 1980s (León Quant 1980; Lobatón González and Garcia 1981). What resembles the reactive strategy used to be the "conventional" control strategy used in the Cotton Belt before the PHF sprays were introduced in the 1960s (Mistric and Mitchell 1968). The conventional approach practiced in the Cotton Belt was based on the EIL concept with an infestation rate of $10 \%$ punctured squares as the triggering point to start insecticide sprays. The conventional strategy and the reactive strategy used monitoring for signaling the start of the insecticide sprays. The reactive strategy is informed by the detection of aggregation spots, while the conventional strategy invoked a damaged squares threshold. Both strategies depend on the reliability of these detection methods and their ability to forecast future damages of economic relevance. The conventional strategy was not effectively implemented due to low adoption of scouting by farmers and economic infeasibility of monitoring by crop advisors in a region where most cotton fields were small and scattered. This failure in the implementation of monitoring in the conventional strategy resulted in heavy losses, build-up of large migrant BW populations and numerous insecticide sprays for preventing large weevil populations from recolonizing the crop (Ewig and Parencia 1949; Mistric and Covington 1968; Mistric and Mitchell 1968). The conventional control strategy was also used in the Colombian Caribbean before the development of the reactive strategy. However, scouting was considered imprecise and expensive and eventually replaced by the detection of aggregation spots as the signal to start the insecticide sprays. Damage thresholds were still used to assess the effectiveness of the control of the aggregation spots and occasionally as signals for the start of entire-field sprays (Bonacelly López et al. 2005).

Nonzero EVPI values were observed for onset of field infestation, loss damage rate and attainable yield (Fig. 5). Collecting additional information on the variables that have nonzero EVPI could be helpful for better determining the efficiency of the assessed strategies. We are especially interested in the promotion of the proactive strategy, because it has the potential to reduce the use of synthetic insecticides. Determining the onset of field infestation is important for reducing uncertainties related to this strategy. Nevertheless, consultants (as the ones assessing and developing management strategies) should not be willing to spend more than the estimated amounts (EVPI) for further investigating selected variables.

\section{Probabilistic analysis}

The modeling approaches we applied allowed for the incorporation of expert knowledge and elicitation of uncertainties. In this way, the model identifies and describes available options for pesticide-based BW management in the Colombian Caribbean. The uncertainties, elicited from experts for feeding the model, reflect the current state of the participants' knowledge on each pest management strategy. The model in this study presents the costs and revenues of BW management at farm scale only. Area-wide management and other factors are also important to the wider social and ecological systems related with the control of this pest. Off-farm benefits of pest management, such as a reduction in the use of synthetic pesticides, are important from an environmental and public health perspective. They may not influence the decision making of farmers, but they are clearly of relevance, and in some cases even the motivation behind regulations that enforce certain practices, especially with regard to IPM. The results constitute a solid foundation for further analyses on BW control at farm scale by assessing the effect of additional (less common or complementary) strategies carried out by farmers for BW control (Burbano-Figueroa et al. 2019). To more fully capture the current situation of BW management in the target region, assessment of the relative profitability of complementary control actions against the boll weevil may also be needed. The holistic modeling approach demonstrated in this analysis can easily be tailored to compare other complementary farm-scale control actions and area-wide control strategies against BW.

\section{Conclusions and recommendations}

We presented a general approach to assessing benefits of pest management at farm scale. We apply expert knowledge in the design and parameterization of models of costs, benefits, risks, and uncertainties of farm-scale control strategies for the BW. The revenue distributions of the modeled control strategies were ordered by stochastic dominance showing that under the current BW infestation pressure, a proactive strategy is more efficient than a reactive strategy. A better understanding of uncertain factors in the proactive strategy, such as the pest infestation pressure, will facilitate its adoption. Currently, this quantification is based on a prior that assumes that the weevil 
will arrive early in the field in all crop seasons. This assumption results in unnecessary insecticide applications when the infestation pressure is low. Additional research should be pursued with the aim to provide a forecast tool that can eliminate this uncertainty and facilitate the adoption of a proactive strategy by all cotton farmers. The results and methods of this study promise to be useful in the assessment and design of IPM strategies.

Supplementary Information The online version contains supplementary material available at https://doi.org/10.1007/s10340-021-01409-9.

Acknowledgements We thank local farmers, crop advisors and members of the Regional Cotton Committee (and its affiliated institutions) and Turipaná Research Center for their participation in this research. Special thanks to Marcela Osten Ballesta and Aura Contreras Patillau for assistance with data compilation, stakeholder meetings and interviews. This research was supported by the German Academic Exchange Service (DAAD), the Foundation fiat panis, the Center for Development Research (ZEF) at the University of Bonn and the Corporación Colombiana de Investigación Agropecuaria (AGROSAVIA).

Author contributions $\mathrm{OBF}, \mathrm{EL}$ and $\mathrm{CB}$ conceived and designed the work. OBF, EL and CW provided methodology. OBF and ASM collected, analyzed and interpreted data. OBF, CW and EL performed visualization. OBF and ASM drafted the manuscript. EL, CB and CW substantively revised the manuscript. OBF contributed to funding acquisition. EL and CB performed supervision.

Funding Open Access funding enabled and organized by Projekt DEAL. Funds for the field research in Colombia were provided by the Foundation fiat panis and the German Academic Exchange Service (DAAD). Open Access funding was provided by Projekt DEAL.

Data availability All data generated during this study was uploaded to an Open Science Framework (OSF) repository (https://osf.io/wv4tg).

Code availability All code generated during this study is available as supplementary information and in the repository https://osf.io/ wv4tg.

\section{Declarations}

Conflicts of interest The authors declare that they have no conflicts of interest.

Consent for publication Individual participants provided informed consent for publication. AGROSAVIA also provided consent for this publication in the matter of proprietary rights.

Ethics approval and consent to participate This research received ethical clearance by the Research Ethics Committee of the Center for Development Research, University of Bonn. Informed consent was obtained from individual participants in this study. All farmers participated in this research under the cooperation framework of AGROSAVIA and farmers associations. Personal data was not collected and/ or stored.

Open Access This article is licensed under a Creative Commons Attribution 4.0 International License, which permits use, sharing, adaptation, distribution and reproduction in any medium or format, as long as you give appropriate credit to the original author(s) and the source, provide a link to the Creative Commons licence, and indicate if changes were made. The images or other third party material in this article are included in the article's Creative Commons licence, unless indicated otherwise in a credit line to the material. If material is not included in the article's Creative Commons licence and your intended use is not permitted by statutory regulation or exceeds the permitted use, you will need to obtain permission directly from the copyright holder. To view a copy of this licence, visit http://creativecommons.org/licenses/by/4.0/.

\section{References}

Aaberge R, Havnes T, Mogstad M (2013) A theory for ranking distribution functions. Statistics Norway, Research Department, Oslo

Agronet (2018) Base de datos de producción, área y rendimiento del cultivo de algodón en la región Caribe. In: http://www.agronet. gov.co/estadistica/Paginas/default.aspx. Accessed 7 Sep 2018

Anderson J, Dillon JL, Hardaker B (1977) Agricultural decision analysis. The Iowa State University Press, Ames

Bonacelly López C, Mendoza Olivella A, Bonilla Buitrago R et al (2005) El Algodonero: Manejo integrado del cultivo en el Caribe seco. Valle del Cesar y Sabanas de Sucre y Bolívar. Corporación Colombiana de Investigación Agropecuaria (CORPOICA), Ibagué

Burbano-Figueroa O, Montes-Mercado KS (2019) Data describing Upland cotton cultivars and advanced breeding lines used in Colombia. Data Brief 25:104140. https://doi.org/10.1016/j.dib. 2019.104140

Burbano-Figueroa O, Sierra-Monroy A, Grandett Martinez L, et al (2021) Management of the Boll Weevil (Coleoptera: Curculionidae) in the Colombian Caribbean: A Conceptual Model. J Integ Pest Manage 12:2021-2016. https://doi.org/10.1093/jipm/pmab0 09

CIMMYT (1988) La formulación de recomendaciones a partir de datos agronómicos: un manual metodológico de evaluación económica. CIMMYT, México D. F.

CONALGODÓN, SENA, SAC, FFA (2008) Biología y manejo del picudo del algodonero en la región Costa-LLanos. Confederación Colombiana de Algodón, Bogotá

Ewig KP, Parencia R (1949) Early-season application of insecticides for cotton-insect control. United States Department of Agriculture. Agricultural Research Administration, Bureau of Entomology and Plant Quarantine, Texas

Gandhi DK, Saunders A, Sugars EG (1981) Stochastic dominance: an application to the insurance portfolio decision. Geneva Pap Risk Insur Issues Pract 6:51-62. https://doi.org/10.1057/gpp.1981.22

Genest W, Stauffer WR, Schultz W (2016) Utility functions predict variance and skewness risk preferences in monkeys. Proc Natl Acad Sci USA 113:8402-8407. https://doi.org/10.1073/pnas. 1602217113

Gómez Lopez U (1981) Manejo del picudo Anthonomus grandis Boheman en el cultivo del algodonero en el Valle del Sinú. El Algodonero 13:30-33

Grandett-Martinez L, de Leon NL, Jiménez Mass N (2003) Análisis del efecto de las parcelas trampas temprano sobre el comportamiento del picudo del algodonero. Temporadas algodonera 2002-2003. CORPOICA, Montería

Hadar J, Russell WR (1969) Rules for ordering uncertain prospects. Am Econ Rev 59(1):25-34

Hardee DD, Harris FA (2003) Eradicating the boll weevil (Coleoptera: Curculionidae): a clash between a highly successful insect, good scientific achievement, and differing agricultural philosophies. Am Entomol 49:82-97. https://doi.org/10.1093/ae/49.2.82

Heilman MD, Namken LN, Norman JW, Lukefahr MJ (1979) Evaluation of an integrated short-season management production system 
for cotton1. J Econ Entomol 72:896-900. https://doi.org/10.1093/ jee/72.6.896

Hubbard D (2014) How to measure anything: finding the value of intangibles in business, 3rd edn. Wiley, Hoboken

Hubbard D, Millar M (2014) Modeling resilience with applied information economics (AIE). Technical Consortium, A Project of the CGIAR, Nairobi

ICA (2009) Plan nacional para el establecimiento, mantenimiento, declaración y reconocimiento de áreas libres y de baja prevalencia del picudo algodonero Anthonomus grandis Boheman en Colombia. Instituto Colombiano Agropecuario, Bogotá

ICA (2010) Resultados de vigilancia fitosanitaria sobre picudo del algodonero: Anthonomus grandis Boheman-en Colombia. ICA, Colombia

Jiang G-T, Fan Z-P, Liu Y (2018) Stochastic multiple-attribute decision making method based on stochastic dominance and almost stochastic dominance rules with an application to online purchase decisions. Cognit Comput 11:1-14. https://doi.org/10. 1007/s12559-018-9605-6

Kay R, Edwards W, Duffy P (2016) Farm management, 8th edn. McGraw-Hill Higher Education (US), New York

Kay R, Edwards W, Duffy PA (2019) Loose leaf for farm management, 9th edn. Mcgraw-Hill Education, New York

Koops MA (2004) Reliability and the value of information. Anim Behav 67:103-111. https://doi.org/10.1016/j.anbehav.2003.02. 008

León Quant G (1980) Algunos aspectos claves en el manejo integrado del picudo del algodonero Anthonomus grandis Boh. El Algodon 12:23-32

Leshno M, Levy H (2004) Stochastic dominance and medical decision making. Health Care Manag Sci 7:207-215. https://doi.org/ 10.1023/b:hcms.0000039383.54736.65

Levy H (2016) Stochastic dominance. Springer International Publishing, Cham

Lobatón González V, Garcia I (1981) Algunos aspectos de la biología del picudo del algodonero Anthonomus grandis Boheman (Coleoptera: Curculionidae). Sociedad Colombiana de Entomología, Montería

Luedeling E, De Leeuw J (2014) Decision modeling for the Habaswein-Wajir Water Supply Project in Northern Kenya. World Agroforestry Center, Nairobi

Luedeling E, Shepherd K, de Leeuw J et al (2014) The application of decision analysis modelling for investment targeting. Technical Consortium, A Project of the CGIAR, Nairobi

Luedeling E, Oord AL, Kiteme B et al (2015) Fresh groundwater for Wajir ex-ante assessment of uncertain benefits for multiple stakeholders in a water supply project in Northern Kenya. Front Environ Sci. https://doi.org/10.3389/fenvs.2015.00016

Luedeling E, Goehring L, Schiffers K, Whitney C, Fernandez E (2021) Quantitative support of decision making under uncertainty. Contributed Package to the R Programming Language, Version 1.106. CRAN. https://cran.r-project.org/web/packages/ decisionSupport/index.html

Mistric WJ, Covington BM (1968) A preventive boll weevil control program applied to a ten-square-mile area within an untreated county. J Econ Entomol 61:186-190. https://doi.org/10.1093/ jee/61.1.186

Mistric WJ, Mitchell ER (1968) A preventive boll weevil control program applied to a ten-square-mile area within a treated county. J Econ Entomol 61:179-186. https://doi.org/10.1093/jee/61.1.179

Moore JL, Runge MC, Webber BL, Wilson JRU (2011) Contain or eradicate? Optimizing the management goal for Australian acacia invasions in the face of uncertainty. Divers Distrib 17:10471059. https://doi.org/10.1111/j.1472-4642.2011.00809.x

Moreno-Moran M, Burbano-Figueroa O (2017) Dynamics of cotton ramulosis epidemics caused by Colletotrichum gossypii var. cephalosporioides in Colombia. Eur J Plant Pathol 149:443454. https://doi.org/10.1007/s10658-017-1194-9

Muller A, Stoyan D (2002) Comparison methods for stochastic models and risks, 1st edn. Wiley, Chichester

Mumford JD, Norton GA (1984) Economics of decision making in pest management. Annu Rev Entomol 29:157-174. https://doi. org/10.1146/annurev.en.29.010184.001105

Ñañez LC (2012) Manejo fitosanitario del cultivo del algodón (Gossypium hirsutum). ICA, Bogotá D. C.

Norton GA (1976) Analysis of decision making in crop protection. Agro-Ecosystems 3:27-44. https://doi.org/10.1016/0304-3746(76) 90098-6

Osorio-Almanza L, Burbano-Figueroa O, Martinez-Reina A (2018) Factibilidad técnica de variedades de algodón expresando proteínas Cry tóxicas contra Anthonomus grandis en el Valle del Sinú, Colombia. Rev Cien Agri 15:47-60. https://doi.org/10.19053/ 01228420.v15.n2.2018.8395

Parma AM, NCEAS Working Group on Population Management (1998) What can adaptive management do for our fish, forests, food, and biodiversity? Integr Biol 1:16-26. https://doi.org/10. 1002/(SICI) 1520-6602(1998)1:1\%3c16::AID-INBI3\%3e3.0. $\mathrm{CO} ; 2-\mathrm{D}$

Pedigo LP, Hutchins SH, Higley LG (1986) Economic injury levels in theory and practice. Annu Rev Entomol 31:341-368. https://doi. org/10.1146/annurev.en.31.010186.002013

Pemsl D, Waibel H (2007) Assessing the profitability of different crop protection strategies in cotton: case study results from Shandong Province, China. Agric Syst 95:28-36. https://doi.org/10.1016/j. agsy.2007.02.013

Perrin RK, Winkelmann DL, Moscardi ER, Anderson JR (1983) Formulación de recomendaciones a partir de datos agronómicos: un manual metodológico de evaluación económica. CIMMYT, México D. F.

Ross SM (1995) Stochastic processes, 2nd edn. Wiley, New York

Rothschild M, Stiglitz JE (1970) Increasing risk: I. A Defini J Econ Theory 2:225-243. https://doi.org/10.1016/0022-0531(70) 90038-4

Ruett M, Whitney C, Luedeling E (2020) Model-based evaluation of management options in ornamental plant nurseries. J Clean Prod. https://doi.org/10.1016/j.jclepro.2020.122653

Rummel DR, White JR, Carroll SC, Pruitt GR (1980) Pheromone trap index system for predicting need for overwintered boll weevil control. J Econ Entomol 73:806-810. https://doi.org/10.1093/jee/ 73.6.806

Shaked M, Shanthikumar JG (2007) Stochastic orders. Springer, New York

Shea K, Possingham HP, Murdoch WW, Roush R (2002) Active adaptive management in insect pest and weed control: intervention with a plan for learning. Ecol Appl 12:927-936. https://doi.org/ 10.1890/1051-0761(2002)012[0927:AAMIIP]2.0.CO;2

Showler AT (2004) Assessment of pre-emptive insecticide applications at pinhead square size for boll weevil control. National Agricultural Library, United States Department of Agriculture, San Antonio, pp 1689-1692

Showler AT (2012) The conundrum of chemical boll weevil control in subtropical regions. In: Perveen F (ed) Insecticides-Pest Engineering. InTecha, Croatia

Showler AT, Robinson JRC (2005) Proactive spraying against boll weevils (Coleoptera: Curculionidae) reduces insecticide applications and increases cotton yield and economic return. J Econ Entomol 98:1977-1983. https://doi.org/10.1603/0022-0493-98.6.1977

Sierra-Monroy JA, Burbano-Figueroa O (2020) Marco regulatorio del manejo del picudo del algodonero (Anthonomus grandis Boheman) en Colombia. Rev Cien Agri 17:67-83. https://doi.org/10. 19053/01228420.v17.n1.2020.10599 
Spiegel A, Britz W, Finger R (2018) Risk, risk aversion and agricultural technology adoption a combination of real options and stochastic dominance. International Association of Agricultural Economists, Vancouver

Stern VM, Smith RF, van den Bosch R, Hagen KS (1959) The integration of chemical and biological control of the spotted alfalfa aphid: the integrated control concept. Hilg 29:81-101. https://doi.org/10. 3733/hilg.v29n02p081

Sunstein CR, Ullmann-Margalit E (1999) Second-order decisions. Ethics 110:5-31. https://doi.org/10.1086/233202

Wafula J, Karimjee Y, Tamba Y et al (2018) Probabilistic assessment of investment options in honey value chains in Lamu County. Kenya Front Appl Math Stat. https://doi.org/10.3389/fams.2018.00006

Waibel H (1986) Bases of micro-economic analysis of chemical crop protection measures. The economics of integrated pest control in irrigated rice. Springer, Berlin, pp 66-85

Whitney CW, Tabuti JRS, Hensel O et al (2017) Homegardens and the future of food and nutrition security in southwest Uganda. Agricultural Systems 154:133-144. https://doi.org/10.1016/j.agsy. 2017.03.009
Whitt W (2014) Stochastic ordering: theory and overview. In: Balakrishnan N, Colton T, Everitt B et al (eds) Wiley statsref: statistics reference online. Wiley, Chichester

Wu Y, Sun X, Xu H et al (2017) A new stochastic dominance degree based on almost stochastic dominance and its application in decision making. Entropy 19:606. https://doi.org/10.3390/e19110606

Yepes Rodriguez F (1997) Consideraciones básicas sobre picudos (Coleoptera: Curculionidae) de importancia económica en Colombia. Universidad Nacional de Colombia, Medellín

Yigzaw N, Mburu J, Ackello-Ogutu C et al (2019) Stochastic impact evaluation of an irrigation development intervention in Northern Ethiopia. Sci Total Environ 685:1209-1220. https://doi.org/10. 1016/j.scitotenv.2019.06.133

Publisher's Note Springer Nature remains neutral with regard to jurisdictional claims in published maps and institutional affiliations. 